\title{
Tungiasis: a poorly-known diagnosis in Europe. Two paradigmatic cases from Portugal
}

\author{
Rui Pedro Santos ${ }^{\circledR}$, Cristina Resende ${ }^{1}$, Maria da Luz Duarte ${ }^{1}$, Celeste Brito ${ }^{1}$
}

\begin{abstract}
Tungiasis is a cutaneous parasitosis caused by infestation of the skin by gravid fleas of the genus Tunga, mainly Tunga penetrans. This flea is very common in tropical and subtropical regions of the globe, but not in Europe. The infestation is acquired by walking barefoot or lying in places where the flea is present, usually beaches or sandy soils. We report two unrelated cases of imported tungiasis in Portugal that presented to our clinic in the same week. We draw attention to one of the most common dermatological diseases in travelers returning from tropical countries, the diagnosis of which is primarily clinical but nonetheless is largely unfamiliar to clinicians attending those patients.
\end{abstract}

Keywords: travel, neglected diseases, skin parasitology, Tunga

Received: 30 June 2017 | Returned for modification: 26 July 2017 | Accepted: 16 August 2017

\section{Introduction}

Tungiasis is a parasitic skin disease caused by the female sand flea of the genus Tunga. Only the species Tunga penetrans and rarely Tunga trimamillata cause the disease in humans (1). It is an exclusively tropical ectoparasitosis that occurs in South America, the Caribbean, and Sub-Saharan Africa (2).

Around the world this disease is also known by various names such as chigoe, jigger, sand flea, puce-chique, kuti, suthi-pique, niguas, bicho do pé, or pulga de bicho (3). This parasitosis is acquired by walking barefoot or lying on soil containing gravid female fleas (2-6).

There are significantly differences in the epidemiology, clinical presentation, and complications between the disease in tourists and in inhabitants of endemic areas (2). Whereas it is a benign and auto-limited disease in travelers, it can be a debilitating and incapacitating disease in people living in endemic areas and suffering from severe infestations (2).

We draw attention to one of the most common dermatological diseases in travelers returning from tropical countries. The diagnosis is primarily clinical, but nonetheless is largely unfamiliar to clinicians attending those patients.

\section{Case report}

The authors present two similar but unrelated clinical cases that presented to our clinic within a week.

The first patient was a healthy 55-year-old Caucasian male presenting with a mildly pruritic growing nodule on his left sole. The patient had noticed the growing lesion for 2 weeks. He had spent 3 weeks of leisure travel in Natal, Brazil, from which he had returned 2 weeks earlier. The dermatological examination revealed a white to yellowish solitary, firm nodule, measuring $5 \mathrm{~mm}$ in diameter, located in the left sole near the base of the first metatarsal bone. The nodule had a crateriform black central area and peripheral scaling (Fig. 1). The patient complained of mild pruritus and a foreign body sensation that caused growing discomfort when walking.

The second case was a healthy 61-year-old Caucasian male that presented a similar lesion, on the same anatomical site, for about 2 weeks (Fig. 2). This patient had the same symptoms and he also had a history of recent travel, in this case to São Tomé and Príncipe, an African island, from which he had returned 2 weeks earlier. A dermoscopy was performed and showed a white halo, peripheric bluish-gray areas, and a central pore with a brown structure (Fig. 3).

Both patients stated that they had walked barefoot on the beach. Combining the clinical and dermoscopic data, a diagnosis of tungiasis was made and a surgical excision was performed. In both cases the histopathological examination revealed an oval structure immediately beneath the stratum corneum bordered by a thick capsule with multiple eggs and parasite exoskeleton fragments morphologically compatible with Tunga penetrans (Figs. 4-5). Both patients were given tetanus booster doses and there was no need for systemic antibiotics. The surgical excision was curative with complete recovery after 2 weeks.



Figure 1 | Patient 1, left plantar nodule with crateriform black central area and thick peripheral scaling. 


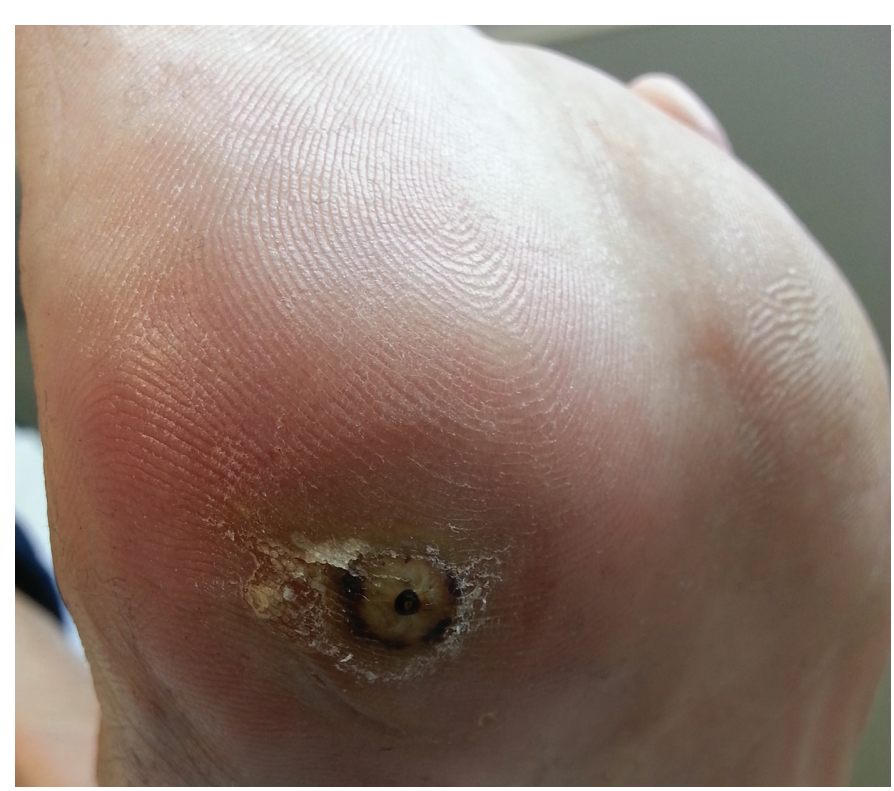

Figure 2 | Patient 2, left plantar nodule with crateriform black central area and thick peripheral scaling.



Figure 3 | Patient 2, dermoscopy: note the white halo corresponding to the enlarged abdomen of the parasite, the peripheral bluish-gray areas corresponding to the exoskeleton, and the central pore with a brown structure corresponding to the posterior part of the parasite.

\section{Discussion}

Tungiasis is a common disease in tropical and subtropical countries, and is a classic poverty-associated disease (2). The prevalence reaches more than $50 \%$ of the population in some hyperendemic areas $(3,5)$. In such countries, there are recurrent and massive infestations with dozens of parasites present on the foot, which can cause considerable morbidity such as superinfections and handicap. This infestation is more common in the dry season $(1,5)$. In developed countries, the majority of cases are travelers returning from endemic areas (3).

Tunga penetrans is one of the smallest fleas in the world, measuring about $1 \mathrm{~mm}$ in diameter (5). The infestation is usually acquired through direct contact with sandy soil, although the flea has the ability to jump up to $20 \mathrm{~cm}$ (5). Only the gravid female flea encysts in the host's skin (5). The flea burrows headfirst into the epidermis, leaving the posterior part of the abdomen visible through an opening in the skin. This configuration allows the parasite to feed on the blood vessels of the dermis and at the same

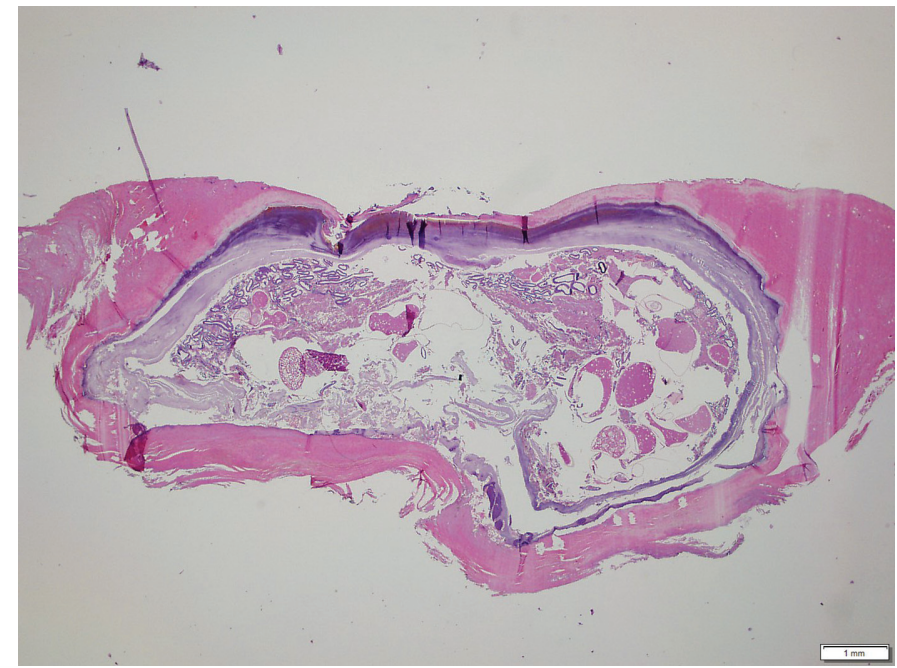

Figure 4 | Thick capsule involving the parasite's exoskeleton and eggs (H\&E, $20 \times)$.

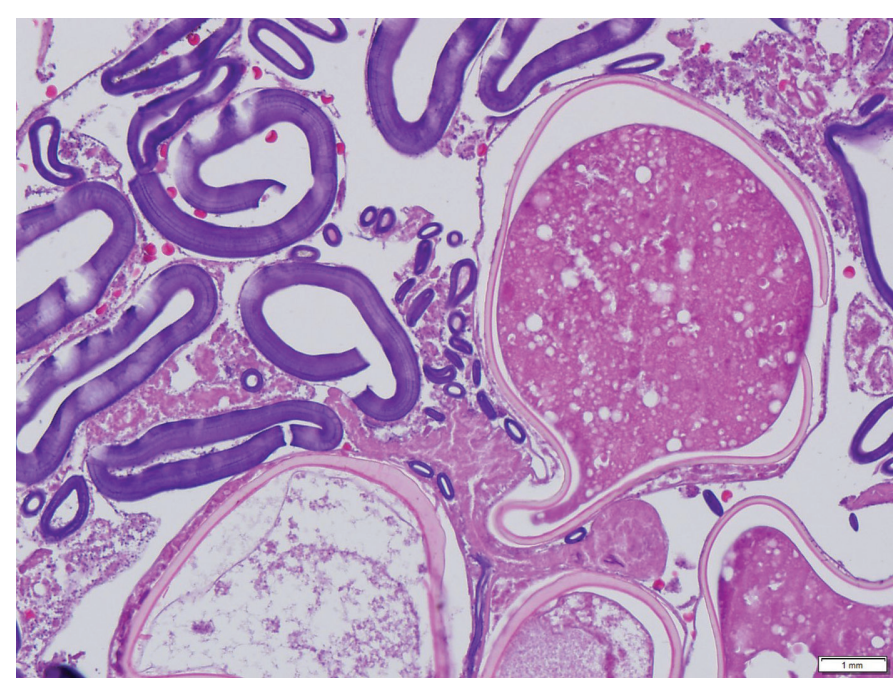

Figure 5 | Detail of the parasite's eggs and fragments of the exoskeleton (H\&E, 20x).

time breathe, defecate, and expel eggs through the opening on the skin surface $(2,7)$. The burrowing process is asymptomatic, but as the flea enlarges (reaching up to $1 \mathrm{~cm}$ ) it can create pain, pruritus, and a foreign body sensation (3). After a period of about 5 weeks, during which it releases hundreds of eggs, the flea eventually dies and is sloughed (3). In both of our cases, the infestation probably occurred 2 to 3 weeks earlier and the flea had already grown and was causing symptoms.

Due to the flea's characteristics and environment, most lesions are found on the feet, often in the periungueal folds, the sole, or the heel, although they can be found in other locations (6).

The diagnosis of tungiasis is mainly clinical. It usually presents with papular or nodular lesions, either single (in travelers) or multiple (in inhabitants of endemic areas) with a white, gray, or yellowish color and a small brown to black central opening corresponding to the posterior portions of the abdomen of the flea (2).

Dermoscopy is progressively being used to aid the diagnosis of several dermatological conditions, and tungiasis is no exception. The classical characteristics, all seen in the patient in whom we performed dermoscopy, are a brown to black central pore corresponding to the posterior part of the parasite, a white halo corresponding to the enlarged abdomen of the parasite, and peripheral bluish-gray areas corresponding to the parasite exoskeleton $(8,9)$.

The treatment of choice is complete surgical excision of the lesion (7). Antibiotics may be indicated if a secondary infection develops. Prophylaxis against tetanus is strongly advised $(2,3,5,6)$. 
Travelers should be advised not to walk barefoot in endemic areas and to inspect their feet daily (5).

Complications are rare in the traveler's form of the disease, but it can be very worrisome. The most common complications are bacterial superinfections, with the risk of tetanus always present (6). In our cases, a tetanus vaccine was administered to both patients.
We present these cases to emphasize a tropical disease that is likely to become increasingly common in developed countries due to the increasing tendency toward globalization. Dermatologists must therefore be aware of it in order to rapidly treat and prevent complications.

\section{References}

1. Linardi PM, Beaucournu JC, de Avelar DM, Belaz S. Notes on the genus Tunga (Siphonaptera: Tungidae) II-neosomes, morphology, classification, and other taxonomic notes. Parasite. 2014;21:68.

2. Feldmeier H, Keysers A. Tungiasis-a Janus-faced parasitic skin disease. Travel Med Infect Dis. 2013;11:357-65.

3. Sachse MM, Guldbakke KK, Khachemoune A. Tunga penetrans: a stowaway from around the world. J Eur Acad Dermatol Venereol. 2007;21:11-6.

4. Korzeniewski K, Juszczak D, Jerzemowski J. Skin lesions in returning travellers. Int Marit Health. 2015;66:173-80.

5. Lefebvre M, Capito C, Durant C, Hervier B, Grossi O. Tungiasis: a poorly documented tropical dermatosis. Med Mal Infect. 2011;41:465-8.

6. Veraldi S, Valsecchi M. Imported tungiasis: a report of 19 cases and review of the literature. Int J Dermatol. 2007;46:1061-6.

7. Palicelli A, Boldorini R, Campisi P, Disanto MG, Gatti L, Portigliotti L, et al. Tungiasis in Italy: an imported case of Tunga penetrans and review of the literature. Patho Res Pract. 2016;212:475-83.

8. Abarzua A, Cataldo K, Alvarez S. Dermoscopy in tungiasis. Indian J Dermatol Venereol Leprol. 2014;80:371-3.

9. Criado PR, Landman G, Reis VM, Belda W, Jr. Tungiasis under dermoscopy: in vivo and ex vivo examination of the cutaneous infestation due to Tunga penetrans. An Bras Dermatol. 2013;88:649-51. 